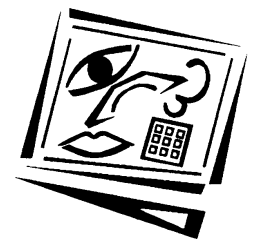

\title{
Using blogging and laptop computers to improve writing skills on a vocational training course
}

\author{
Nick Marsden and Eileen Piggot-Irvine \\ UNITEC New Zealand
}

\begin{abstract}
The action research project described in this paper was part of an initiative to bring about change in the way courses are delivered in the vocational trades area at UNITEC New Zealand. We decided to focus on students' writing on a new Level 3 course - the Certificate in Automotive and Mechanical Engineering (C.A.M.E.) in which all participants had netbooks or laptops for the first time. We selected blogging because it introduces new possibilities in a field where one would not expect to see much written work by students. Using the Problem Resolving Action Research (PRAR) model (PiggotIrvine, 2009), we approached the project in three stages. At the reconnaissance stage it was clear that writing skills did not enjoy a position of priority. We gauged the C.A.M.E. students' attitudes to writing in general, and to digital technology via the use of a questionnaire and a focus group. We then implemented new approaches to teaching using digital technology in response to perceived needs. At the evaluation stage, we collected further responses via a questionnaire and a focus group on the students' attitudes to blogging and digital technology. Key findings included that the students were not discouraged by writing tasks, nor by digital technology, and that vocational tutors may need to play a more active role in embedding writing in courses.
\end{abstract}

\section{Introduction}

The Certificate in Automotive and Mechanical Engineering (C.A.M.E.) course is delivered by the Department of Automotive Technology at UNITEC New Zealand, a large government tertiary provider that serves the Auckland region. The start of 2010 saw the launch of three major teaching and learning change process initiatives across the institution. These were:

- UNITEC's e-learning initiative: an institutional decision was made in 2009 to upgrade our use of information and communication technology (ICT), particularly incorporating Web 2.0 applications in learning and teaching;

- The (2009-2011) government sponsored initiatives around embedding language, literacy and numeracy in programs which cater for levels 1-3;

- UNITEC's Living Curriculum strategy, which is embodied by principles such as conversation (teachers become facilitators and co-learners, learners become investigators, seekers and problem solvers), curiosity/ enquiry, collaboration, selfefficacy, problem solving, reflection, and creativity.

The above three institutional initiatives are significant and, arriving all at once, they represent a whirlwind of change which does not come without its challenges. At the institutional level there is recognition of the need to move with the times and to adopt 
up to date technologies, but this seems to be easier said than done. For the teachers involved it means a significant identity shift, not least because of the changed dynamics suggested between teachers and learners. Changing from being a 'guardian' and 'editor' of knowledge to being a 'steward' will require some careful development, not only in terms of technology. Guy Merchant alerts us to this when he asks the important question: "How easy is it to leave the comfort zone of conventional, classroom based student-teacher relationships and experiment with new and fluid online interactions? Virtual worlds can be unfamiliar and chaotic environments in which conventional routines and control strategies are of little use. Teachers will have to take risks when using this technology, and both teachers and researchers need to document the new ways of working that emerge." (Merchant, 2009, p108).

In an attempt to monitor the ICT upgrade, we undertook an action research based change project under the supervision of Eileen Piggot-Irvine. This research project acknowledged the 'risks' taken by a group of vocational teachers who experimented with a digitalised environment. The risk factor was not entirely unexpected because it was uncharted territory for the automotive tutors. We were mindful of the fact that "ejournals, e-portfolios and blogs have the potential to move the locus of control from the teacher to the learner." (Robertson, 2007, p 9). The C.A.M.E course (Level 3 Certificate in Automotive and Mechanical Engineering) and its digital inclusion is an entirely new way of working for the teachers involved, and there will be a great deal to learn from the experience. The Automotive Department set out to design a course that would be holistic in its approach, and one in which students could develop study skills, along with a range of core life skills, including ICT skills. We decided that researching the writing component of the course would be one way to manage and inform the changes. In many ways the institutional change initiatives fall in line with rapid developments in digital literacies and Web 2.0 tools, which promote social learning. However, making the transition to e-learning tools cannot be done overnight, and the decision to switch from traditional toolboxes full of spanners and wrenches, to laptops, was met with resistance by many staff, even though workshop tools are provided by the institution for use in class workshops.

The specific focus of the project was to determine student attitudes to writing blogs on this Level 3 vocational course, and to see how this might augment the amount and nature of students' writing during their course of study. The research area was aligned to the Tertiary Education Commission's (TEC's) commitment to raising the profile of literacy, and in particular, writing to communicate. The definition of literacy here includes digital literacies in which course participants use laptops, working with applications such as blogger.com, PowerPoint and YouTube, in order to present their vocational coursework.

This paper is an attempt to evaluate how the use of such digital literacy technologies can enhance the learning experience for vocational students. At the same time, we intend to shed light on some of the implications for tutors. We hope that the project will inform the 'new ways of working', and that it will also generate further enquiry into ways that technologies can support the teaching and learning of writing skills.

The overarching research question used for the project was:

How can blogging be used to improve students' writing on the Level 3 Certificate in Automotive and Mechanical Engineering course? 
The research question was intended to get an idea of how far writing can be made meaningful to students, using technologies which are now commonplace in the world of work and leisure. Focusing on digital literacies, and in particular, the use of blogs, enabled us to consider factors such as purpose and audience, which are key elements in writing to communicate, and which are measurable using the TEC's Foundation Learning Progressions (Tertiary Education Commission, 2008). Using blogs has also allowed for communication and comment between course participants and tutors, and to some extent, it has made the processes of written communication more collaborative in design, and more purposeful in nature. As well as ascertaining attitudes, it is hoped that adapting to new technologies in the way we teach and learn will inform us of ways to enrich the writing component in vocational courses.

\section{Background literature}

It is hard to find instances where radical changes in the way we do things, brought about by technological changes, have not caused tensions at the same time as creating exciting new ways of operating. The steady growth of ICT in education, as in all walks of life, has been rapid. As Gordon (2000) says: "Whether or not we choose to be, we are actors in the drama of technological progress. As the Internet takes up residence in our offices, homes and schools, we no longer have the prerogative to view technology as optional." (p 3) More and more ways of using technology in teaching and learning contexts are being developed and explored. Our reading about digital literacy tells us clearly that educators who ignore digital literacies risk doing students a great disservice. According to Carrington and Robinson (2009), "It is time our classrooms became places where digital and print literacies come together to allow children opportunities to develop the skills and attitudes they will need to navigate complex urban sites and social forms." (p 3).

The relevance becomes obvious when you go to an automotive workshop. Young graduates from an automotive course in 2011 will likely be using computers during parts of their day. They may use diagnostic tools or they may just need to enter details on a computer of a car that has been serviced. Their tasks will certainly involve some writing. In addition to that, mechanics may also need to be able to look up manufacturer's specifications online, and order parts, which may involve writing an email. At the more difficult end of the scale, a workshop employee may have to write detailed descriptions of repair jobs (perhaps for insurance or legal purposes). In the light of UNITEC initiatives around literacy, the ICT needs of graduates (and the ICT demands of a course) have to be met. At the same time, we had to attempt to unpack what these graduates will need to write in their chosen vocation. If this is not addressed in context, in a course of study, we believe that educators are overlooking an important skill set which is now mandatory in many workplaces.

Developments in ICT have changed the power dynamics in communication and they afford us new and varied ways to communicate with more people. In terms of writing, they may not teach us how to write, but they may encourage us to write more, simply because there are more means available. Developments in applications and tools are also associated with getting more of us to write because the tools themselves (blogs, email, text, Twitter, YouTube, etc.) are widely owned and are to be found in all walks of life. In the light of this, it is not hard to see how digital technology is impacting on education. For teachers in any discipline, the need to upskill with digital technology has become unavoidable. New technologies will mean new capability requirements, 
and this suggests that teachers unfamiliar with tools such as blogging, will themselves need scaffolded guidance and support.

According to the United Kingdom Literacy Association, "blogs are now a wellestablished and widely recognised form of digital communication, and this alone suggests that they should be taken seriously in educational settings." (Davies \& Merchant 2009, $\mathrm{p}$ 91) This transition needs to be made with care because the dynamics of teaching and learning are changing, giving the learner more agency and scope.

Because of the changing dynamics, teachers will become what Wenger (2009) terms 'technology stewards' ( $\mathrm{p} 24)$. This role emerges with e-learning pedagogy, and it is one which requires not only content knowledge, but also technological knowledge, because as Wenger (2009) states: "Technology stewarding adopts a community's perspective to help a community choose, configure, and use technologies to best suit its needs." Further, Wenger believes that technology "increases the complexity of the group/individual polarity" (p. 59). Teachers implicitly and explicitly have a stewarding role when it comes to negotiating a course of study using up to date technology. Students can now access knowledge from many sources, in a digital habitat, and it can develop the characteristics of what Wenger calls a "community of practice" ( p 3).

For the teacher using Web 2.0 technology, content knowledge is not enough, and lecturing may no longer be the most prized skill. Teachers are also responsible for running and managing e-learning on a programme coherently. How blogs are used in any given course therefore, needs to be carefully handled. Giving feedback and support on assignments is a direct responsibility of the teacher, and as this is done using ICT, the teacher needs to scaffold the use of ICT, to establish effective procedures and processes to give feedback, support, and to assess student work. These processes have the potential to provide a much more collaborative approach to learning. Blogs can be used as a tool for reflecting, describing, arguing a case, etc, and they can also invite responses from peers - all actions which lend themselves to enquiry, reflection and learning. We need to contrast this stewarding role with a traditional teacher's role. "Most of what teachers consider teaching and assessment consists of marking and correcting students' work. This kind of practice does not engage our students in those rich interactive processes of talking about their work and their ideas." (Glogowski, 2009, p 1).

Digital technology has many affordances that help with enquiry and self-efficacy. Learners can engage at a level beyond the learning community, as well as within it. With stewardship (Wenger, 2009), learners can turn to all kinds of sources for knowledge and learning, ranging from searches carried out by themselves, to peer collaboration, and to on-line support materials. Clearly, technological tools have altered teaching and learning dynamics. Teaching need no longer simply involve the transmission of knowledge, but can foster a social constructivist approach, driven by enquiry and curiosity, where the journey of learning is more important than the traditional destination - the exams. These features are embodied in the notion of a living curriculum, and as exams will no longer be the be all and end all in terms of course assessment, the management of assessed components will need to take into account any course work done in e-portfolios, blogs, or other means, because learning does not occur only within the confines of lecture hours and homework tasks, or within and from the confines of an institution. 
Learning on a vocational course is not a disconnected activity. It is an activity that demands connection with the outside world, and connectivity between participants. Blogging, posting homework assignments using PowerPoint, YouTube and so on can help to provide these links. Assuming that when students enjoy taking the initiative in their learning it is an indicator of their motivation, then to ignore opportunities which encourage autonomy and self-reliance would be an egregious oversight. Previous research on blogging has held similar aspirations, that "...the capabilities of blogging for self presentation and social interactivity would assist students to forge a stronger sense of personal empowerment and expressive entitlement, on the one hand, and increased connection to a shared learning community, on the other." (Farmer, Yue \& Brooks, 2008, p.2).

There are now many exponents (Carrington \& Robinson, 2009; Gordon, 2000; Leu, 2004; Merchant \& Davies, 2009; Wenger, 2009) of the value and relevance of digital literacies, and the following quote captures the spirit of the arguments in favour of adopting ICTs in education:

\begin{abstract}
While it is clear that many new literacies are emerging rapidly, we believe the most essential ones for schools to consider cluster around the Internet and allow students to exploit the extensive ICTs that become available in an online, networked environment. In an information age, we believe it becomes essential to prepare students for these new literacies because they are central to the use of information and the acquisition of knowledge. Traditional definitions of literacy and literacy instruction will be insufficient if we seek to provide students with the futures they deserve. (Leu, Kinzer, Coiro \& Cammack, 2004, p. 1571)
\end{abstract}

\title{
'Real world learning'
}

'Who expects to do much writing on a Level 3 automotive course?' would be a fair question to ask. Traditionally, vocational trades courses have (in many ways) been seen, at worst, as courses that can be done by those who failed school, or at best as courses for people who are good with their hands, but who are not 'academic types'. The writing component might range from writing an essay, or at least a paragraph, on the advantages and disadvantages of say, diesel fuel - or there might be little or no writing component. Tutors themselves might shun writing as part of their perceived identity of being 'non-academic', and they may lean more towards the practical side of the subject, such as the business of taking engines apart. Further, it could be argued that the essay fails to meet the needs of Level 3 automotive students since it does not meet their future employment needs. Graduates from a Level 3 Automotive course are not likely to be required to write essays about engines or cars, but they might well need ICT skills to order parts online, or to send an email to a customer. They might conceivably need to describe, in writing, a procedure they have followed in a repair job - perhaps for legal purposes. It seems logical to offer opportunities for these more relevant acts of writing within a course of study.

\section{Rationale for introducing laptops for Automotive Level 3}

The Certificate in Automotive and Mechanical Engineering is a six component course which has been designed to conflate 30 unit standards. This process has involved a complete document rewrite, and the aim was to replace the fragmentary unit standards approach with something more holistic. Two significant educational changes were being embedded in UNITEC courses at the same time. These were: 
1. e-learning: embraced by UNITEC as a whole, with the aim of making most courses include an 'e-component'; and

2. demonstration of the government's commitment to literacy skills development in the tertiary education strategy.

Semester 1, 2010 was the first time a UNITEC automotive course had required all participants to have a laptop. This was achieved through creative reconfiguring of the way the students spent their NZ\$1,000 study allowance. Traditionally all participants on an automotive course were required to purchase the following with their NZ\$1,000 allowance:

- overalls;

- protective clothing such as boots and gloves;

- two volumes of Ed May's Automotive Mechanics for \$200; and

- a box of tools for about $\$ 400$.

For the C.A.M.E. course, the last two requirements were dropped. Instead, students were asked to purchase netbooks worth $\$ 600$. This toolbox decision was met with resistance from many staff, who felt that possessing a toolbox was the first priority in any automotive course. There was no resistance to getting rid of the textbook requirement, however, as many tutors did not use it as a resource in their classes. The counter argument to the tool issue was that laptops were also versatile 'tools'. After all, you can look up any tool you care to on the Internet. The laptop had the potential to develop other capabilities, such as writing and reading, and in an educational institution, these are core skills. The laptops opened up access to a range of websites such as http:/ / www.autoshop101.com/ and http://www.howstuffworks.com/ that are rich sources of material.

In Semester 1, 2010, there were 80 enrolments for the new C.A.M.E. course. Of these, 24 were Youth Guarantee students - students considered to be 'at risk' - who may have failed to engage in the school system, and who are targeted as needing extra funding support in order that they might have a better chance of future employment. The 24 Youth Guarantee students were all loaned a netbook for the duration of the course.

The introduction of laptops had implications for the tutors. The idea of walking into a room where each student has their own laptop - and they might all have their backs to you while they are ensconced online - was quite a scary one. There was no resistance to the idea from the students, nor the tutors directly involved. However, there was some resistance from other automotive tutors not directly involved in the course, who expressed sentiments ranging from scepticism, to outright disdain for the project. Notwithstanding, among the recommendations for good practice suggested by Farmer et al (2008), tutors need to encourage and model risk taking, and the C.A.M.E. tutors have certainly done that.

\section{Methodology for the action research}

This research received UNITEC ethics approval and all participants in the course (48) completed consent forms and questionnaires for the reconnaissance and evaluation stages of the research. In addition to the questionnaires (see Appendices 1 and 2), we held two focus groups of up to ten students to revisit and expand upon responses in the questionnaires. 


\section{Research approach}

The research project followed the Problem Resolving Action Research - PRAR model (Piggot-Irvine, 2009), using an iterative process of planning, acting, observing, and reflecting. There are multiple models of action research and, as noted in Piggot-Irvine and Bartlett (2008):

\footnotetext{
Models of action research differ in representation. Some have an upward depiction of the iterative or cyclical direction (see Piggot-Irvine, 2001): others are downward (see Kemmis \& McTaggart, 1990). Models also differ in uniformity. Kemmis and McTaggart's model, for example, is linear in sequence of activity, as is Corey's (1953) early and linear problem-solving approach to action research (p.19)
}

The model used in this project shows some similarity to the Kemmis and McTaggart (1990) model but is re-orientated to show upward progression in the research. It also differs by incorporating spin-off cycles that were originally suggested by McNiff (1988) to demonstrate that alternative cycles of activity can be expected in action research and are part of a "continuous improvement approach" (Piggot-Irvine, 2009, p 13).

At the planning stage of this project, because of the switch to e-learning and each student having a laptop, we decided to limit our focus to the impact of this technology on the teaching and learning in relation to writing. The main stages to the research project were reconnaissance, implementation and evaluation, which are shown in Figure 1.

A key factor in our approach was flexibility, because we wanted to be able to respond to needs that emerged. The cyclical nature of the process allowed for critical reflection and discussion at different stages. Each stage produced 'spin-off cycles', enabling us to identify issues and to plan new courses of action. We believe that action research is an effective tool that can inform change management, and the fact that this research involved the participants in an examination of their own program adds to its relevance. We hope that it will also be a way to maximise the participants' involvement in the change process.

\section{Reconnaissance}

At the reconnaissance stage we discovered that prior to the C.A.M.E. course, students at Level 3 used to receive 30 booklets with many 'gap-fill' tasks. Often writing events were at word level, but seldom went beyond sentence level. Acts of writing on an automotive Level 3 course rarely involved critical insight or reflection, and considerations of purpose and audience were not major features of writing tasks. In short, there was little to encourage students to develop their ability to write to communicate. For this reason, we chose to gauge the new cohort's attitudes to writing in general, as well as their attitudes to using e-learning tools. We used a questionnaire on writing preferences and habits (see Appendix 1) to gain this feedback. In addition to this, we held a focus group discussion to expand on the questionnaire responses and to discuss issues arising from using Web 2.0 applications such as blogger.com.

The questionnaire results provided interesting information on a variety of student perceptions on the use of writing generally and ICT. The students noted multiple ways that they used writing and these are summarised in Table 1. 
THE PRoblem Resolving Action ReseARCH (PRAR) MODEL

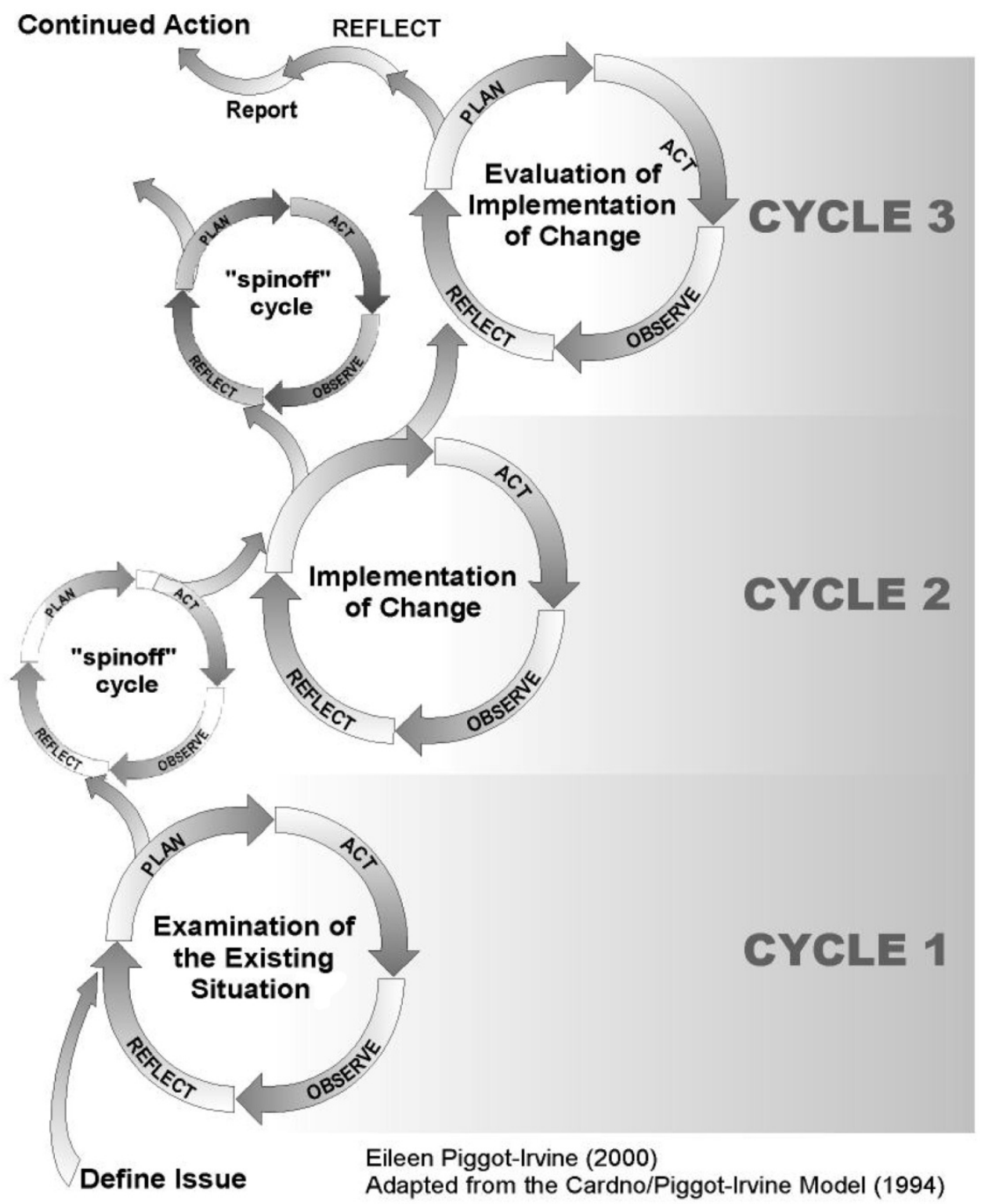

Figure 1: The Problem Resolving Action Research model

The key messages we took from this table were:

- the students engage in a range of writing activities in their daily lives, and that many of these involved ICT (particularly texting);

- some of the acts of writing involve writing at length, but it was no surprise that most did not have to write long reports; 
- many of the students in this class have never been in work, and it is understandable that few have experience of completing work forms, logs, invoices and receipts. It also highlights an area where tutors might provide input and support. There are a number of forms used in the Automotive Industry that could be incorporated here, Warrant of Fitness (the New Zealand roadworthiness test for vehicles) documents being just one example; and overall, we felt it showed that students expected to engage in a certain amount of writing, which could be seen as an opportunity to further develop writing skills during their course.

Table 1: Types of writing used by students

\begin{tabular}{|c|c|c|c|c|}
\hline & Every day & Every week & Occasionally & Never \\
\hline Formal letters or emails & 6 & 14 & 21 & 8 \\
\hline Personal letters or emails & 7 & 14 & 20 & 8 \\
\hline Short reports (less than one page) & 3 & 13 & 21 & 8 \\
\hline Long reports & 0 & 12 & 25 & 9 \\
\hline $\begin{array}{l}\text { Work forms such as logs, records, } \\
\text { invoices, receipts }\end{array}$ & 4 & 8 & 20 & 16 \\
\hline Course assignments & 15 & 26 & 6 & 2 \\
\hline Text messages & 35 & 3 & 8 & 4 \\
\hline Meeting minutes or notes & 1 & 16 & 11 & 20 \\
\hline Websites, blogs & 23 & 19 & 9 & 1 \\
\hline Other (list, diary) & 3 & 8 & 18 & 16 \\
\hline
\end{tabular}

The comments provided by students are reported upon under each of the following questions from the questionnaire.

How do you feel about writing?
Hate it: 6
OK: 36
Love it: 2

The suggestion here was that most respondents did not feel intimidated by writing. The feedback from the six students who 'hate writing' was useful in that it indicated an area where the tutor needed to think of ways to engage students more.

How good do you think you are at writing?

Not at all: 12 Quite good: $28 \quad$ Very good: 9

These responses indicated a level of confidence and familiarity with the act of writing. Nine respondents clearly felt good about their writing. It also showed gaps, and areas where teachers might employ deliberate acts of teaching, support and feedback processes around writing skills.

How confident do you feel about writing in your daily life?

Not at all: 9 Quite confident: $31 \quad$ Very confident: 4

These responses reinforced the points raised in the previous question.

How important is writing for you in your daily life?

Not at all: $13 \quad$ Quite important: 24 Very important: 7

The result was another indication of areas where tutors could begin to plan interventions which supported the development of writing skills needed for this vocation. The majority of the class - by far - felt that writing was either quite or very 
important. This may or may not indicate that students would expect to be attending to their writing on a course of study at an educational establishment.

\section{Our reflections on the questionnaire results}

We felt that it was essential to gauge affective factors. How students feel about writing is a better focus than how students feel about the technology because we considered that this could blur the focus on writing skills per se. Our instincts told us that focusing on technology might 'blind' students, and the focus on writing could be lost. Reading between the lines, the students clearly felt unfazed by technology. That 18 of the respondents felt they would keep writing blogs after they finished their course was an eye-opener! This suggests that it is perceived as a relevant activity to be involved in. It was heartening to see that only six respondents 'hate writing'. We noticed that this cohort contained a critical mass of interest which could provide teachers with ways to gain traction in the area of writing to communicate. Also heartening was that many students felt that they were at least OK with writing, and only nine in the sample said they were unconfident. Almost two thirds of the respondents felt that writing was either 'quite important' or 'very important' in their daily lives. These comments seem consistent with Andrea Lunsford's findings, whose 2009 Stanford University Study of Writing (of college students' prose) concludes that today's students are writing more than ever before in history.

From the focus groups, we were able to gather unanticipated student feedback, particularly in relation to the kind of support tools and tutor support they expected. It was reassuring to hear that all of the students felt that the technology was relevant to their learning. Indeed, the learners were able to critically identify ways in which the specific application of blogging could be made more useful. All of the students in the focus groups agreed that ICT skills would be useful to them in their lives. The thing that stood out most was that the students felt that blogging would go hand in hand with practical work, and this was a significant piece of feedback for the tutors about the management of blogging on the C.A.M.E. course.

\section{Implementation}

At the start of 2010, the C.A.M.E. tutors themselves had not had experience of a class full of students with laptops. We decided to introduce blogging as a way of encouraging students to reflect, and to write something - no matter how short - in relation to what they were learning. At the outset, it was not easy for the tutors to get this going, but they managed by setting an in-class exercise where everyone was asked to blog about 'the best car in the world'. Simple interventions like this one proved to be effective. Another intervention was the decision to purchase eight palm-held digital cameras.

Early in the semester we had a visit from a highly skilled enthusiast, Philip Court, who had built his own electric racing car - http://greenstage.co.nz/. The students filmed Phil's car and used some of the images in class presentations. Some noticed that Philip had his own website and his own blogspot. The same was true of the next esteemed visitor, Bill Dubé, who brought in an electric dragbike. Both use websites and both are bloggers. Facts about the drag bike are on http://www.killacycle.com/about/. If they wanted to, the students could follow the blogs of these experts. As a matter of interest, both the vehicles that were studied are electric powered, and this in itself helped the 
students to make critical connections with issues such as sustainability, and environmental considerations. There are clearly many new and emerging ways learners can use to access information and share knowledge. Early in semester 1, 2010, it was quickly becoming apparent that on this course, many ICT skills could be used to enhance learning, and blogging was just one of the new dimensions.

Over the course of the research, the C.A.M.E. team held weekly tutor planning meetings, and we were able to discuss the results of the reconnaissance questionnaire. We decided on two main courses of action:

1. Students needed guidelines and support with the blogs; and

2. Tutors would encourage blogging and writing around workshop activities.

In addition to the above, we reviewed the students' performance on a National Assessment Tool, using the Foundation Learning Progressions (FLP), which were developed by the New Zealand Tertiary Education Commission (TEC). We set out to introduce considerations such as purpose and audience, planning and composing, and revising and editing into the blogging framework. We also devised interventions for the blogs and a framework for students for reviewing their blogs (Figure 2).

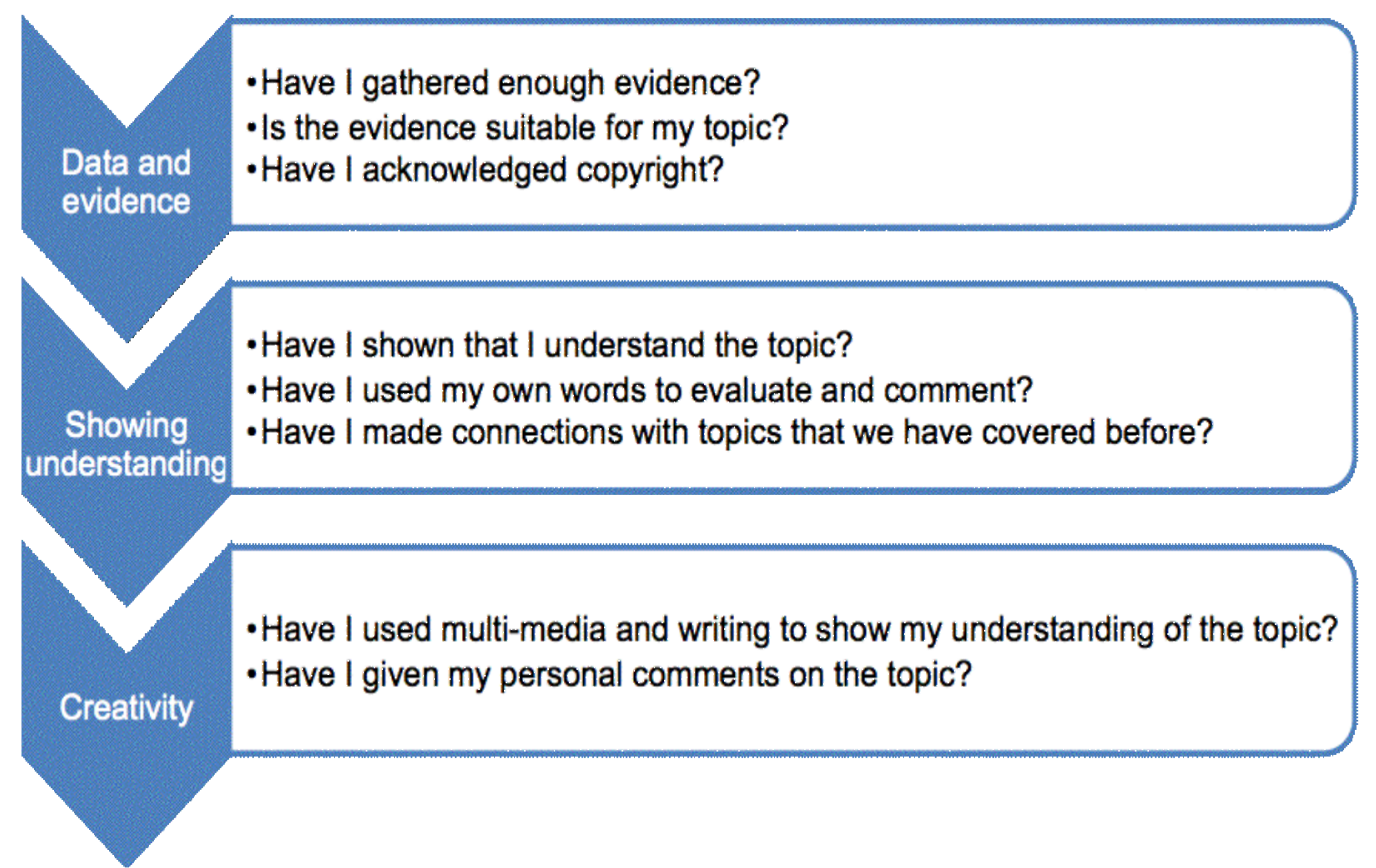

Figure 2: Student guidelines for writing their blogs

As well as a framework for self-editing, teachers provided scaffolded intervention in class, and supported these with online help tools. We promoted the FLP framework on planning for writing further (in weeks 8 and 9). We began to consider ways of making collaborative reflection a requirement, to widen the audience beyond the teacher. Learners were encouraged to read and comment on each others' blogs, although only the confident writers wanted to share their work with other students. 


\section{Evaluation}

Throughout the project we saw the Certificate in Automotive and Mechanical Engineering students working on their own accord on projects well beyond their class hours. Traditionally this would only happen when students are 'kept behind'. This definitely indicated some kind of shift in responsibility for learning, and it is a good indicator of motivation and agency.

Our sampling of the blogs showed that some students were putting a great deal of time and effort into writing them. A handful of students were very comfortable with the process, and produced writing of good quality. One or two of the blogs were outstanding, and many were of a good standard, revealing engagement with course content, reflection and critical thinking. However, the class profile in relation to writing skills was 'spiky', with National Assessment Tool results for writing ranging from Step 2 to Step 6, showing a variable from quite poor to good. It was evident from some students' blogs that they were not writing a great deal, and tutors probably needed to spend more time addressing this.

In the evaluation stage questionnaire we explored the students' use of blogs specifically. Once again, we report on the results under each of the questionnaire questions.

Did you use blogs in your everyday life before the C.A.M.E. course? Everyday: 5 A little: $6 \quad$ Not at all: 32

Clearly some students had some familiarity with blogging, but many did not. To us this result indicated the need to carefully set up processes such as blogging, and not to assume that all students would automatically be willing participants. Students needed to see the value of blogs, and also how they related to their course. Clarity of purpose was key, particularly when students were being assessed on blog contributions.

Do you like writing blogs?

Yes: $28 \quad$ No: 11

Our first response to this result was one of surprise that students were not concerned about having to write blogs for their course.

Do you write more than usual now that you are blogging for your course? Yes: 33 No: 8

Most in the sample indicated that on the whole they were producing more writing. Whilst we were aware that some students were more active as bloggers than others, we did not feel that the eight people who said 'no' to this question were necessarily inactive.

What things do you find helpful for writing your blogs?

Online support: 11 Tutor guidance and feedback: 26 Feedback from classmates: 9

This result clearly shows that there was an expectation of support for students' writing and for tutor guidance and feedback in particular. This has implications for the expected skills set for vocational tutors. It seems reasonable to assume that support is provided. 
Do you enjoy writing blogs more than you did before?

Yes: 27 No: 16

Some students were extremely motivated by the process of developing an e-portfolio, part of which included blogging. For some, the process was less important than the practical aspects of the course. It was heartening to see that some of the students could see themselves blogging in the future.

Do you think you will keep writing blogs after you have finished your course? Yes: 18 No: 13 Don't know: 8

This result corresponds with the response given by many students in the focus groups. The students could see the point of writing blogs on the course, but they were unsure whether they would continue. The focus group participants felt that they would need to have a good reason to keep writing, as many of them said they did not always have something to say. However, they felt comfortable with the structured tasks and activities they had used. Not all the students were confident about sharing their work with other students, but they felt that they would get used to it.

Do you find writing blogs using multi-media to be: Very useful: $19 \quad$ Quite useful: $25 \quad$ Not useful: 0

This final response was illuminating because not one of the respondents felt that blogging had no relevance. We discussed the fact that had blogging been replaced with the word 'essays', the response might have been entirely different. Clearly students could see a place for blogs, indicating that this medium is a legitimate and relevant form of expression for these students.

As a follow-up to the questionnaire, we invited a delegation of 10 students to a focus group meeting. This consisted of informal discussions about the use of blogging and other ICT skills. For the discussion we used the same questions from the questionnaire, because students were familiar with them. We felt that revisiting the issues raised would be a good way to focus the discussions. Their comments indicated that they were enjoying the blogging and also the use of YouTube and PowerPoint for their presentations and their e-portfolios. They stressed that their main interest was working on cars, and that sometimes they wished they could do more of that on the course. They said they would blog more if they spent more time in the workshop doing 'practical stuff', as they enjoyed filming their work. They could then put this on YouTube and embed it in a presentation, complete with music, 'fly-in' captions and their favourite music. The team of C.A.M.E. teachers agreed that this was a surprise finding, and a positive one.

Only five of the students said they would blog after the course. One thought it was 'awesome'. All the participants agreed that it was helpful when tutors gave them guidelines.

\section{Other results and our reflections}

There are multiple spin-offs from the project. We provide these along with reflections that we have drawn from the project and we have categorised these as positives, negatives, and 'of interest'. 


\section{Positive}

- The first thing we noticed about each student having a laptop was the sharp rise in motivation. Whilst not all students were immediately comfortable with it, there was little or no resistance to the idea. As the questionnaire responses indicate, all the students seem to feel that blogging and multimedia tools are useful.

- As previous Level 3 Automotive courses involved little in the way of reflective writing, it is fair to say that using blogs and multimedia has led to an increase in acts of writing. A handful of students have been able to excel in their written work. Two in the group attained Step 6 in the Literacy National Assessment Tool for writing. Three achieved Step 5, and the majority in the sample tested at Step 3.

- The process has allowed for student reflection, feedback and dialogue around writing. Tutors are now providing more support. Guidelines have been written for students with suggestions on how learners can structure their blogs. Tutors have also used correction codes for students to self-correct their work.

- Some of the student PowerPoint presentations, which typically include YouTube clips of them working on their own cars, graphics, 'fly-ins', music and so on, have been outstanding, and indicate that the learners have taken pride in their work.

- The fact that learners have an opportunity to use and develop ICT skills is a bonus.

- It has altered the lecturers' view of themselves as educators. Lessons are now inherently student-centred.

- There has been a great deal of interest from other tertiary providers, such as Manukau Institute of Technology (Auckland), Northtec, and Bay of Plenty Polytechnic. Members of the C.A.M.E. team, and the change project team, presented aspects of the course (e.g. student e-portfolios) at the September 2010 UCOL conference in Palmerston North ('Who's in the Driving Seat?'), at the Bridging Conference in Wellington, and to the Motor Industry Trade Organisation (MITO). The C.A.M.E. team also had an open classroom policy, allowing other staff from the institution to observe how the classes are conducted.

- There were over 500 expressions of interest from prospective students who wanted to enrol in the 2011 C.A.M.E. cohort.

\section{Negative}

- Many lecturers lack the confidence and skills to deliver and manage a course in this way. Without a considered program of support and teacher development, lecturer up-skilling could be haphazard.

- Vocational trades lecturers may feel that they do not have the confidence to tackle issues with writing.

- Unless wireless broadband capability, connectivity and computer access issues are in place, both students and staff may experience frustration with the process. 


\section{Of interest}

- The C.A.M.E. program has been controversial within the trades department. Many lecturers are not excited about changing to online or mixed mode delivery. Many feel it would amount to relinquishing control. Some teachers have struggled to envisage their role in this kind of teaching. There is also no doubt that some feel threatened by the new directions being taken in teaching and learning. An immediate spin-off of the institutional change is that Automotive and Mechanical Engineering pathways beyond Level 3 now have to be revised. Students leaving the C.A.M.E. course may struggle when they revert back to 'chalk and talk', and Unit Standard booklets in Level 4 . Levels 4 and 5 courses are now being overhauled, starting with document rewrites, and e-learning is to be a key feature.

- Whilst the students remained upbeat about using laptops for their study, they felt that at times they were not doing enough practical work in the workshop. When we asked tutors, they said they were going to address this imbalance but it would mean the blogging would taper off. However, interestingly, the students suggested the opposite. They felt that if they had more opportunities to do workshop tasks, it was likely they would be motivated to write more in their blogs, to support their YouTube clips. In other words, more hands on material would boost their motivation to build their blogs with more images and words. This finding makes sense, and the tutors will need to bear it in mind for future courses.

- There is more to be done to support writing on vocational courses. We feel that some discourse analysis on acts of writing for any given course or trade would be extremely beneficial in that it might help to highlight 'real world' acts of writing that can be incorporated on such courses.

\section{Conclusions}

The results from the project suggest that blogging has increased the amount of writing that automotive Level three students do in the course of their studies, but there is still work to be done to support the process of developing the quality of student writing. The main areas that need attention seem to be:

- teacher development on how to manage the tools, and how best to scaffold writing tasks - including how to give help with written expression, text layout, appropriateness of language and writing conventions; and

- the technological capability of the teaching staff needs to be supported by professional development workshops, and in-service training.

If the teachers are able to further identify conventions and styles in automotive acts of writing, and as long as their interventions are well timed, scaffolded, and relevant, we believe it is an effective way to raise the literacy bar in relation to writing on vocational courses. As Clive Thompson (2009) says:

Of course, good teaching is always going to be crucial, as is the mastering of formal academic prose. But it's also becoming clear that online media are pushing literacy into cool directions. The brevity of texting and status updating teaches young people to deploy haiku-like concision. 
At the end of a trial year for C.A.M.E. we concluded that 'the cool factor' that comes with this new technology is not to be ignored, because if used appropriately it could go a long way to boost engagement, retention and success, as well as work readiness even for learners who may have hated school.

\section{Acknowledgments}

We acknowledge the participation all members of the C.A.M.E. development/ research team: Vickel Narayan, David Clarke, Sione Kavaliku, Derrick Solomon, Lee Baglow and Niranjan Singh. We would also like to express our gratitude to the students of the C.A.M.E. course, 2010, who were willing participants in this venture.

\section{References}

Anderson-Inman, L. (2009). Thinking between the lines: Literacy and learning in a connected world. On the Horizon, 17(2), 122-141. http: / / dx.doi.org/10.1108/10748120910965502

Corey, S. M. (1953). Action research to improve school practices. New York: Teachers College Press.

Davies, J. \& Merchant, G. (2009). Negotiating the blogosphere. In V. Carrington \& M. Robinson (Eds.), Digital literacies: Social learning and classroom practices. (pp 81-93). Los Angeles: Sage.

Dube, P. (2010). KillaCycle - World's quickest electric motorcycle. http:/ / www.killacycle.com/about/

Farmer, B., Yue, A. \& Brooks, C. (2008). Using blogging for higher order learning in large cohort university teaching: A case study. Australasian Journal of Educational Technology, 24(2), 123136. http:/ / www.ascilite.org.au/ajet/ajet24/ farmer.html.

Garner, R. (2011). Mystery solved: How to get boys to write. New Zealand Herald, 11 February. http: / / www.nzherald.co.nz / lifestyle/ news/article.cfm?c_id=6\&objectid=10705622

Glogowski, K. (2009). The blog of proximal development. http: / / www.teachandlearn.ca/blog/2009/02/20/ thoughts-on-assessment/

Gordon, D. T. (2000). The digital classroom: How technology is changing the way we teach and learn. Cambridge, MA: Harvard Education Letter.

Kemmis, S. \& McTaggart, R. (Eds.) (1990). Action research reader. Geelong, Australia: Deakin University Press.

Leu, D. J. Jr, Kinzer, C. K., Coiro, J. \& Cammack, D. (2004). Toward a theory of new literacies emerging from the Internet and other information and communication technologies. In R. B. Ruddell \& N. Unrau (Eds.), Theoretical models and processes of reading. (pp 1570-1613) Newark, DE: International Reading Association.

http: / / www.reading.org/publications/bbv/books/bk502/ abstracts/bk502-54-Leu.html

Lumsford, A. (2009). Stanford study of writing. http:/ / ssw.stanford.edu/

May, E. (2009). Automotive mechanics (8th ed.). North Ryde, Aust.: McGraw-Hill Australia.

McNiff, J. (1988). Action research: Principles and practice. Basingstoke: Macmillan.

Merchant, G. (2009). Virtual worlds in real-life classrooms. In V. Carrington \& M. Robinson (Eds.), Digital literacies: Social learning and classroom practices. (pp 95-110) Los Angeles: Sage.

Piggot-Irvine, E. (Ed.) (2009). Action research in practice. Wellington: New Zealand Council for Educational Research. http: / / www.nzcer.org.nz/nzcerpress/ action-research-practice

Piggot-Irvine, E. (2000). What is action research? Paper presented to the New Zealand Action Research Network Conference, Christchurch, September.

Piggot-Irvine, E. (2001). Appraisal: Reducing control, enhancing effectiveness. PhD thesis, Massey University, Palmerston North, New Zealand. 
Piggot-Irvine, E. \& Bartlett, B. (2008). Evaluating action research. Wellington: NZCER.

Robertson, I. (2007). Factors influencing vocational teacher's use of online functionalities in Australia. Australasian Journal of Educational Technology, 23(3), 371-389.

http: / / www.ascilite.org.au/ajet/ajet23/robertson.html

Sullivan, K. (2008). Autoshop 101. [verified 31 Dec 2011] http:/ / www.autoshop101.com

Team Greenstage \& Court, P. (2011). Hello, welcome to Greenstage. [verified 31 Dec 2011] http: / / www.greenstage.co.nz/

Tertiary Education Commission (2008). Teaching adults to write to communicate: Using the foundation learning progressions. Wellington: Tertiary Education Commission. http: / / www.tec.govt.nz / Documents / Publications / Learning-progressions-write-tocommunicate.pdf

Thompson, C. (2009, August 24). Clive Thompson on the new literacy. Wired Magazine, 17(9). [verified 31 Dec 2011] http: / / www.wired.com/techbiz/ people/magazine/1709/st_thompson

Wenger, E. (2009). Digital habitats: Stewarding technology for communities. Portland, Oregon: CP Square.

\section{Appendix 1: Action research questionnaire}

Certificate in Automotive and Mechanical Engineering, 2010-2011

Date completed:

The questionnaire below is taken from Appendix B.1, Knowing the learner, 'Attitude to Writing' survey, Tertiary Education Commission (2008), Teaching adults to write to communicate: Using the learning progressions, page 61.

\section{What do you write and how often? (Tick the appropriate boxes)}

\begin{tabular}{|l|l|l|l|l|}
\hline & Every day & Every week & Occasionally & Never \\
\hline Formal letters or emails & & & & \\
\hline Personal letters or emails & & & & \\
\hline $\begin{array}{l}\text { Short reports (less than } \\
\text { one page) }\end{array}$ & & & & \\
\hline Long reports & & & & \\
\hline $\begin{array}{l}\text { Work forms such as logs, } \\
\text { records, invoices, receipts }\end{array}$ & & & & \\
\hline Course assignments & & & & \\
\hline Text messages & & & & \\
\hline Meeting minutes or notes & & & & \\
\hline Websites, blogs & & & & \\
\hline Other (list, diary) & & & & \\
\hline
\end{tabular}

\section{How do you feel about writing? (Please circle the appropriate number)}
HATE IT
OKAY
LOVE IT
1
23
4
5

\section{How good do you think you are at writing? (Please circle the appropriate number)}
NOT AT ALL
QUITE GOOD
VERY GOOD
$1 \quad 2$
3
4 
4. How confident do you feel about writing in your daily life?
NOT AT ALL
1
QUITE CONFIDENT
3
VERY CONFIDENT
$4 \quad 5$

5. How important is writing for you in your daily life?
NOT AT ALL
QUITE IMPORTANT
VERY IMPORTANT
2
$4 \quad 5$

THANK YOU FOR TAKING THE TIME TO COMPLETE THESE QUESTIONS

\section{Appendix 2: Action research questionnaire}

Certificate in Automotive and Mechanical Engineering, 2010-2011

Date completed:

Questions about writing blogs

Please circle the appropriate number and where appropriate answer the question.

1. Did you use blogs in your everyday life before the CAME course?

a. everyday b. only a little c. not at all

2. Do you like writing blogs?

3. Do you write more than usual now that you are blogging for your course?

4. What things do you find helpful for writing your blogs?

a. online support b. tutor guidance and feedback c. feedback comments from classmates

5. Do you enjoy writing blogs more than you did before?

6. Do you think you will keep writing blogs after you have finished your course?

7. Do you find writing blogs using multimedia to be:
a. very useful?
b. quite useful?
c. not useful?

THANK YOU FOR TAKING THE TIME TO COMPLETE THESE QUESTIONS

Authors: Nick Marsden, Te Puna Ako

Private Bag 92025, UNITEC New Zealand. Email: nmarsden@unitec.ac.nz

Eileen Piggot-Irvine, New Zealand Action Research and Review Centre

UNITEC New Zealand. Email: epiggotirvine@unitec.ac.nz

Please cite as: Marsden, N. \& Piggot-Irvine, E. (2012). Using blogging and laptop computers to improve writing skills on a vocational training course. Australasian Journal of Educational Technology, 28(1), 30-47.

http: / / www.ascilite.org.au/ajet/ajet28/marsden.html 